\title{
YKL-40 levels are associated with disease severity and prognosis of viral pneumonia, but not available in bacterial pneumonia in children
}

Xingge Yang and Guangyao Sheng ${ }^{*}$

\begin{abstract}
Background: Viral pneumonia is the main type of community-acquired pneumonia (CAP) in children. YKL-40, a chitinase-like protein, is regarded as a biomarker of the degree of inflammation.

Methods: Children who were diagnosed with CAP, including viral pneumonia, bacterial pneumonia, and dual infection, were included in the cohort study. The pathogenic diagnosis depended on PCR and immunoassay test. YKL-40 levels were examined twice by enzyme-linked immunoassay (ELISA).

Results: Serum YKL-40 levels were higher in patients with pneumonia than in healthy controls. The admission levels of YKL-40 in serum and Bronchoalveolar lavage (BALFs) indicated a positive correlation with the serum levels of C-reactive protein and other inflammatory cytokines (IL-6 and TNF-a). The disease severity have no correlation with the admission serum levels of YKL-40. Meanwhile, reductions in YKL-40 levels from initial admission levels to day 5 post-admission were correlated with disease severity. The multiple logistic analysis indicated the decreased extent of serum YKL-40 level as an independent prognostic predictor of severe cases in patients with viral pneumonia.
\end{abstract}

Conclusions: Reductions in serum YKL-40 levels on day 5 after receiving therapy is a possible prognostic biomarker for children with viral pneumonia.

Keywords: YKL-40, Children pneumonia, Biomarker

\section{Background}

Worldwide, 450 million patients are diagnosed with pneumonia, and approximately 4 million people die from this illness each year [1-3]. It is estimated that 156 million cases in children occur annually, and of these, 151 million occur in developing countries such as China [1]. Viral pneumonia is the most common community-acquired pneumonia (CAP) and a cause of lung infection in children. Approximately, 100 million cases occur every year in children, which accounts for the majority of patients with viral pneumonia [2]. The prognosis depends on various risk factors, including age, immune status,

\footnotetext{
* Correspondence: shengguangyaoo@163.com

Pediatrics, the First Affiliated Hospital of Zhengzhou University, No. 1 East Jianshe Road, Zhengzhou 450052, Henan, China
}

co-infection with bacterial pathogens and the type of pathogenic virus $[4,5]$. The first evaluation as recommended by WHO paper cited by the authors should rely on clinical signs and symptoms, the requirement of supplemental oxygen administration and or ventilatory support, still lacking a rapid and safe method to ensure a diagnosis, exception made for bronchoalveolar lavage or lung biopsy [6].

But the study about the biomarker for evaluation of disease severity and prognosis is still infrequent, which lead to that pediatrician failed to precisely estimate the prognosis. Thus more intensive therapy including admission to the intensive care unit (ICU) more positively and preventive use of antibiotic drugs are not performed. Therefore, it is crucial for clinicians to investigate the

(c) The Author(s). 2018 Open Access This article is distributed under the terms of the Creative Commons Attribution 4.0 International License (http://creativecommons.org/licenses/by/4.0/), which permits unrestricted use, distribution, and reproduction in any medium, provided you give appropriate credit to the original author(s) and the source, provide a link to the Creative Commons license, and indicate if changes were made. The Creative Commons Public Domain Dedication waiver (http://creativecommons.org/publicdomain/zero/1.0/) applies to the data made available in this article, unless otherwise stated. 
biomarkers applicable for the prediction and assessment of prognosis.

YKL-40 is a chitinase-like protein and regarded as a pro-inflammatory cytokine mainly secreted by macrophages, which are involved in the inflammatory response and tissue injury [7, 8]. Hsiang-Ling Wang et al. have revealed that the prognostic value in a cohort of adult CAP and the plasma level of YKL-40 is positively correlated with the severity of CAP depicted by pneumonia severity index (PSI) and CURB-65 score [9]. YKL-40 has been recognized as a prognostic biomarker for ILD (interstitial lung disease) $[10,11]$. Its role as a predictor of outcome in hypersensitivity pneumonia (HP) has also been proved in a recent HP cohort study [12]. But its role in predicting the prognosis of children with pneumonia, especially those with viral pneumonia, is not known.

The aim of present aim is to prove the clinical utility value of YKL-40 in BALF in children with pneumonia. Our study suggest that a clinician could evaluate their patient's prognosis with two consecutive measurements of their YKL-40 serum levels, immediately after admission and day 5 after therapy initiation.

\section{Materials and method}

\section{Study subjects and design}

Children who were diagnosed with CAP, including viral pneumonia, bacterial pneumonia, and dual infection, were consecutively enrolled and their demographic and clinical data were retrospectively analyzed. The age of all children enrolled in the retrospectively study is ranging from 0.8 to 9.6. The mean age was 2.3 years old. The serum levels of YKL-40 in admission and at 5th day after therapy were measured. The clinical outcomes (including the incidence of entrance of ICU, mechanical ventilation and sepsis) and diseased severity was recorded. The correlation between admission levels of YKL-40 or decreased percentage after therapy and clinical prognosis in children with viral infection, bacterial infection and co-infection were analyzed and described respectively. The children who had a history of asthma, or immunodeficiency disease were excluded. The diagnosis of pneumonia was based on clinical characteristics, biochemical examination, cough, fever, and radiography. The diagnostic criteria of pneumonia included the presence of inflammatory exudation (alveolar or interstitial) by the chest X-ray with the simultaneous clinical manifestation of pulmonary infection, including fever, cough and difficult breathing. All patients diagnosed with pneumonia received the standard therapy according to the relevant guidelines for the CAP management in children and adult patients $[13,14]$.

All children or healthy volunteers enrolled in this study were in-patients at our institution from 2014 to 2017. The healthy volunteers included the out-patient children with no evidence of inflammation-related disease requiring a medical examination and collection of serum or blood samples. The retrospective observation study was approved by Medical ethic committee of the First Affiliated Hospital of Zhengzhou University. Informed consent was obtained from all study subjects.

\section{Pathogenic diagnosis}

The sputum specimen was collected from children patients with pneumonia once the diagnosis was verified by chest X-ray. Gram stain, sputum culture were performed for the detection of specific bacterial strains including the Pneumococcus and Haemophilus influen$z a e$ as has been previously described [15]. The diagnosis of viral infection depended on the detection of the viral antigen by quantitative real-time PCR or multiplex RT-PCR following the standard protocols [16]. RNA was extracted from sputum specimens using Trizol (Invitrogen, USA). cDNA was synthesized by reverse transcription. The cyclic temperature settings were $95^{\circ} \mathrm{C}, 30 \mathrm{~s}$; $60{ }^{\circ} \mathrm{C}, 30 \mathrm{~s} ; 65^{\circ} \mathrm{C}, 30 \mathrm{~s}$; amplified by 40 cycles with the last at $65^{\circ} \mathrm{C}$ for $7 \mathrm{~min}$. Human cytomegalovirus (CMV), adenovirus (AV) and parainfluenza virus(PIV) was assayed by fluorescent real-time PCR (BIO-RAD iCycler). For CMV detection, the forward and reverse primers were CMV-F: 5'-AACTGTACGTGCTG TGTGTACTAACTC-3' and CMV-R: 5' -CTCGATAAT GCGTTGTGCACCCCATAA-3', respectively. For AV detection, the primers were AV-F: 5'-TGCGTAGTA GCCCTGGTGAA -3'; AV-R:5'-CATGTAGCGTGGTC GATGGTTC-3'; HPIVs-R: AGGTGACCGTGGGT CCACATG;HPIVs-F:ACTGTAGTAGGTTGTAGCTAG. The cyclic temperature settings were $95^{\circ} \mathrm{C}, 30 \mathrm{~s} ; 60^{\circ} \mathrm{C}$, $30 \mathrm{~s} ; 70^{\circ} \mathrm{C}, 30 \mathrm{~s}$; amplified, 40 cycles.

\section{Definition of endpoint events and evaluation of diseased severity}

The endpoint event for prognostic evaluation is the the incidence of sepsis secondary to pneumonia, use of mechanical ventilation and admission in Intensive Care Unit. The disease severity of the pneumonia was determined by the WHO recommended child pneumonia classification standard and based on clinical signs as previously mentioned, including the non-severe pneumonia, severe pneumonia and very severe pneumonia $[17,18]$. To overcome the limitation of disease assessment by relying solely on the admission levels of YKL-40, we detected the levels of YLK-40 in the serum twice, immediately and on day 5 after admission. We calculated the reduction degree represented by the decreased percentage of YKL-40 levels on day 5 after receiving therapy and then ranked the reduction degree as follows: low group, $\leq 20 \%$; median group, $>20 \%$ but $\leq 50 \%$; and high group $>50 \%$ ). 


\section{YKL-40 and other inflammatory cytokine assays}

BALF was collected via fiber optic bronchoscope as previously described [19]. The patient's serum was collected twice, in admission (once the diagnosis was made immediately and prior to commencement of therapy) and on day 5 after admission. YKL-40 and other inflammatory cytokines, including C-reactive protein, interleukin (IL)-6, IL-10, and TNF- $\alpha$, were examined in serum and BALF samples by enzyme-linked immunoassay (ELISA). The serum levels of YKL-40 were repeatedly measured respectively in admission and at 5th day after admission. The levels of BALF was measured only on admission.

\section{Mechanical ventilation}

For children with severe pneumonia, the mechanical ventilation was applied according to synchronized intermittent mandatory ventilation (SIMV) combination with positive end expiratory pressure (PEEP). The tidal volume was kept in $10-12 \mathrm{ml} / \mathrm{kg}$ in these children. The weaning from mechanical ventilation was according to the improvement of blood oxygen saturation $(\mathrm{FiO} 2>$ $350)$ and normalization of respiratory rate $(<30$ times /min) in autonomous respiration.

\section{Statistical analysis}

Data were analyzed using SPSS software (SPSS, IL, USA) and were presented as the mean $\pm \mathrm{SD}$. The comparison between two groups was conducted by the Student t-test or Wilcoxon's rank test for continuous variables and the Chi-squared or Fisher's exact test for categorical variables. ANOVA was used for the multiple-group comparison. To overcome the limitation of disease assessment by relying solely on the admission levels of YKL-40, we detected the levels of YLK-40 in the serum twice, immediately and on day 5 after admission. We calculated the reduction degree represented by the decreased percentage of YKL- 40 levels on day 5 after receiving therapy and then ranked the reduction degree as follows: low group, $\leq 20 \%$; median group, $>20 \%$ but $\leq 50 \%$; and high group $>50 \%$ ) for the Spearman's correlation analysis between the reduction degree of serum levels of YKL-40 and diseased severity. Spearman's correlation coefficient was obtained for correlation analysis. Univariate and multiple logistic regression analyses were used to analyze the prognostic factors. A $p$-value of $<$ 0.05 was considered as statistically significant.

\section{Results}

\section{Characteristics of study subjects}

Total of 321 subjects were enrolled in this study, including 50 healthy volunteers. The demographic characteristics and laboratory data of the study subjects are shown in Table 1. Regarding the age of the study subjects, no significant differences were found among the groups, including the sole viral, bacterial, and dual infection groups. The disease severity was divided into three classes according to the World Health Organization classification of pneumonia. At baseline, none of the subjects were receiving treatment with corticosteroids; they were all enrolled at the time of diagnosis before receiving therapy. The infection by Pneumococcus was detected in the 145 children and the infection by Haemophilus influenzae was detected in 67 children with pneumonia by sputum examination including direct smearing and sputum culture. The AV, CMV and HPIVs infection was found in 35, 45, 63 children respectively, which indicated that the HPIVs is the major viral pathogen in children viral pneumonia in our institution.

\section{Admission YKL-40 levels in serum and BALFs of children with CAP}

Compared with the healthy controls, serum levels of YKL-40 in children with pneumonia was significantly higher (Fig. 1a). To verify the type of pneumonia was distinguished by YKL-40 levels in the serum or BALF, we compared the levels of YKL-40 in serum and BALF samples in the viral pneumonia and bacterial pneumonia groups (Fig. 1b). We observed no significant difference between the admission levels of YKL-40 in the serum of patients with viral pneumonia, bacterial pneumonia, or co-infection. But the levels of YKL-40 in the BALF specimens of patients with bacterial pneumonia were however significantly higher than those with sole viral pneumonia $(P=0.012)$, and the levels of YKL-40 in the BALF specimens were statistically higher than in the serum specimens from the same individuals $(P=0.007)$. However, in the sole viral pneumonia group, increased levels of YKL-40 in the BALF specimens as compared with the serum specimens was not observed.

\section{The correlation between admission levels of YKL-40 and other inflammatory biomarkers}

The levels of IL-6, TNF- $\alpha$, and C-reactive protein were positively correlated with the serum levels of YKL-40, but the IL-10 levels were negatively correlated with YKL-40 levels in all 3 pneumonia subgroups (Fig. 2a). These results provide evidence that the YKL-40 is a pro-inflammatory cytokine accelerating tissue injury and might have an adverse effect on tissue repair and inflammation resolution. The levels of YKL-40 in the BALF specimens were also slightly positively correlated with the serum levels of C-reactive protein but not with the levels of IL- 6 and TNF- $\alpha$ in all study subjects (Fig. $2 b$ ).

The correlation between admission serum levels of YKL40 and the disease severity of viral pneumonia

The correlation between the admission serum levels of YKL-40 and severity of pneumonia was analyzed using 
Table 1 Baseline demographic and clinical characteristics of study participants

\begin{tabular}{|c|c|c|c|c|c|}
\hline Characteristics & $\begin{array}{l}\text { Healthy controls } \\
(N=50)\end{array}$ & $\begin{array}{l}\text { Viral Pneumonia } \\
(N=104)\end{array}$ & $\begin{array}{l}\text { Bacterial Pneumonia } \\
(N=110)\end{array}$ & $\begin{array}{l}\text { Co-infection } \\
(N=66)\end{array}$ & $P$ value \\
\hline Age (years) & $2.3(0.8-9.6)$ & $1.8(0.2-8.9)$ & $2.2(1.2-12.1)$ & $2.4(0.5-9.7)$ & 0.38 \\
\hline Gender (male, \%) & $34(68)$ & $66(63)$ & $52(47)$ & $39(59)$ & 0.31 \\
\hline Serum YLK-40 (ng/ml) & $6.30 \pm 2.27$ & $18.48 \pm 4.63$ & $19.38 \pm 3.34$ & $19.32 \pm 2.87$ & $<0.001$ \\
\hline TNF-a (pg/ml) & NA & $12.4 \pm 7.85$ & $13.6 \pm 9.28$ & $14.5 \pm 10.23$ & 0.24 \\
\hline IL-6 (pg/ml) & NA & $32.3 \pm 11.25$ & $35.6 \pm 8.17$ & $39.5 \pm 12.1$ & 0.26 \\
\hline hsCRP (mg/dl) & NA & $161.38 \pm 34.78$ & $158.25 \pm 26.90$ & $170.93 \pm 29.36$ & 0.34 \\
\hline IL-10 (pg/ml) & NA & $83.96 \pm 14.89$ & $95.36 \pm 8.98$ & $84.36 \pm 16.98$ & 0.07 \\
\hline BALFs YLK-40 (ng/ml,n) & NA & $26.45 \pm 3.65(18)$ & $34.87 \pm 5.42(34)$ & $33.63 \pm 2.50(21)$ & 0.02 \\
\hline \multicolumn{6}{|l|}{ Severity } \\
\hline Not Severe (\%) & NA & 55.7 & 47.3 & 51.5 & 0.08 \\
\hline Severe (\%) & NA & 24.6 & 32.7 & 11.2 & 0.12 \\
\hline Very Severe (\%) & NA & 19.7 & 30.0 & 27.3 & 0.13 \\
\hline $\mathrm{PO}_{2}(\mathrm{mmHg})$ & NA & $98.1 \pm 1.0$ & $97.2 \pm 2.5$ & $97.0 \pm 3.6$ & 0.41 \\
\hline $\mathrm{SO}_{2}(\mathrm{mmHg})$ & NA & $95.5 \pm 1.8$ & $94.5 \pm 1.3$ & $94.9 \pm 0.9$ & 0.55 \\
\hline WBC $\left(10^{9} / \mathrm{L}\right)$ & NA & $9.8 \pm 4.3$ & $13.9 \pm 3.5$ & $14.2 \pm 4.4$ & 0.008 \\
\hline PCT (ng/ml) & NA & $0.65 \pm 0.26$ & $1.33 \pm 0.49$ & $1.59 \pm 0.87$ & 0.02 \\
\hline Glucocorticoid use ${ }^{a}, n(\%)$ a & NA & 20(19.2) & $14(12.8)$ & $12(18.2)$ & 0.43 \\
\hline
\end{tabular}

Abbreviations: BALF Bronchoalveolar Lavage Fluids, CRP high sensitive C-reactive protein, WBC white blood cell, $P C T$ procalcitonin

${ }^{a}$ Values at the period of hospitalization before colleting the serum sample at the second time

${ }^{\mathrm{b}} \mathrm{P}$ value $<0.05$ was considered significant

the Spearman's correlation coefficient; no significant correlation was observed (Fig. 3a, b and c). We further performed the Spearman's correlation analysis in the different subgroups, and no obvious correlation was shown between the serum levels and disease severity, regardless of the type of pneumonia.

The reduction degree of YKL-40 serum levels after standard therapy serves as an independent risk factor of viral pneumonia in children

Previous results have demonstrated that the admission levels of YKL-40 do not correlate with the disease severity. To determine a correlation with the severity of pneumonia, a univariate correlation analysis was performed. We found a negative correlation between the reduction degree of YLK- 40 levels for the severity of disease and the median length of hospital stay (Fig. 4a and b) in the viral pneumonia group, but not in the bacterial pneumonia or co-infection groups (data not shown). In other words, the higher the percentage reduction in YKL-40 levels indicated the shorter hospital stay in the children with viral pneumonia. The logistic regression analysis identified the independent prognosis factors that were associated with the mechanical
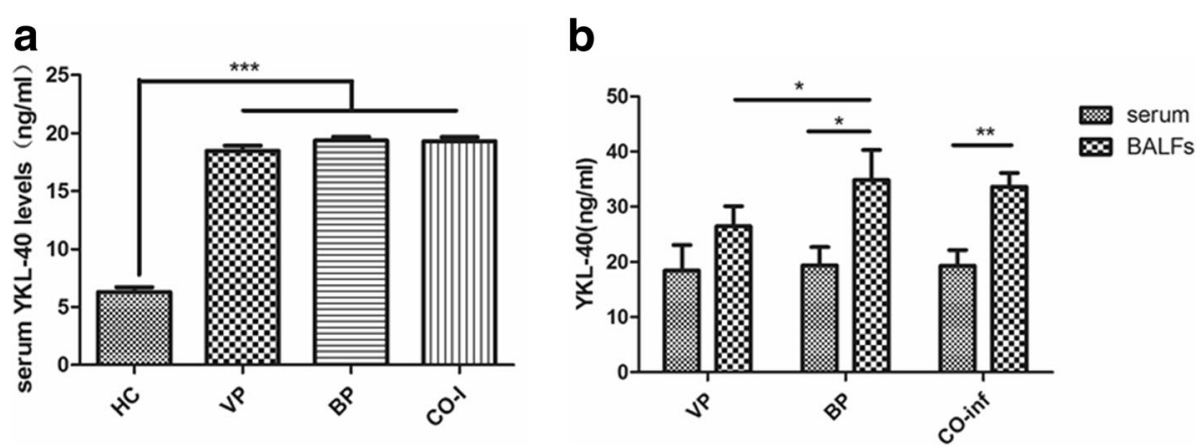

Fig. 1 The admission serum and BALFs levels of YKL-40 in healthy control and child pneumonia. a. The serum levels of YKL-40 in healthy volunteers and different kinds of infectious pneumonia of children. VP, viral pneumonia. BP, bacterial pneumonia. CO-I, co-infection. b. The difference between the serum and BALFs levels as well as the BALFs levels among the VP, BP and co-infection. All data presented by mean \pm SD. *** $P<0.001{ }^{* *} P<0.01 * P<0.05$ 

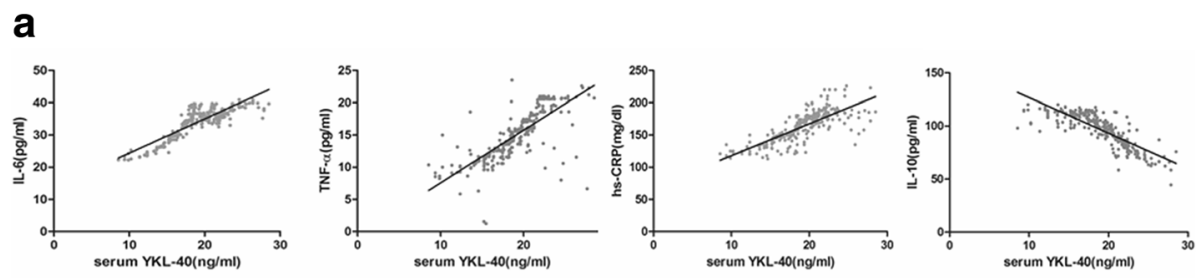

b
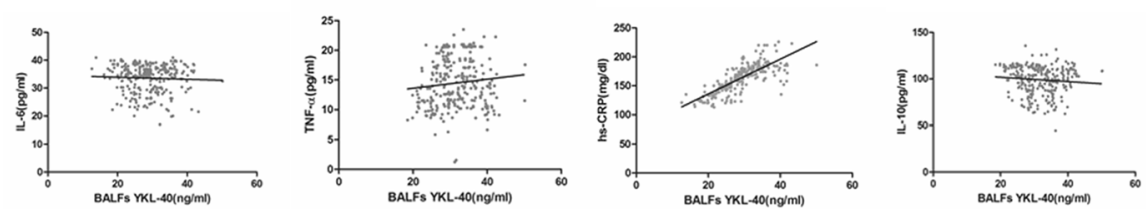

Fig. 2 The linear correlation analysis between YKL-40 levels and classic inflammatory cytokine. a. The correlation between serum levels of YKL-40 and proinflammatory cytokine in circulating, including respectively pro-inflammatory $\mathrm{IL}-6\left(r^{2}=0.73, P<0.0001\right), \mathrm{TNF}-\mathrm{a}\left(r^{2}=0.58, P<0001\right)$, hs-CRP $\left(r^{2}=0.61, P<0.0001\right)$ and anti-inflammation IL-10 $\left(r^{2}=0.67, P<0.0001\right)$. b. The correlation between BALFs levels of YKL-40 and proinflammatory cytokine in circulating, respectively in IL-6 $\left(r^{2}=0.0019, P=0.46\right)$, TNF- $a\left(r^{2}=0.011, P=0.0785\right)$, hs-CRP $\left(r^{2}=0.084, P<0.0001\right)$ and IL-10 $\left(r^{2}=0.0079\right.$, $P=0.14)$. The slight correlation only emerged in between the circulating hs-CRP levels and BALFs levels. The data represented by mean \pm SD, and $P<0,05$ defined as significantly statistic difference

ventilation and ICU admission rates. The factors evaluated in the multivariate logistics regression model included age, history of previous pneumonia, procalcitonin levels, degree reduction of YKL-40 levels, and infectious type (Table 2). The independent risk factors for mechanical ventilation were identified as the age, infectious type, history of previous pneumonia, and reduction degree of YKL-40 levels. The independent risk factors for ICU admission were identified as the age, infectious type, and degree reduction of YKL-40 levels. For sepsis onset, the reduction degree of YKL-40 levels was the only independent risk factor.

\section{Discussion}

The present study revealed the usefulness of YKL-40 in the prognostic assessment of child pneumonia at first, especially in viral pneumonia. Although we could not demonstrate a positive correlation between serum level of YKL-40 and disease severity, the degree of reduction of YKL-40 levels on day 5 after admission could be considered as a prognostic biomarker and might guide the clinical decisions in children with pneumonia (e.g., need more intensive therapy and care, including mechanical ventilation or admission to ICU).

YKL-40, a recently discovered protein, is involved in airway inflammation, a potential biomarker of asthma, and a member of the chitinase and chitinase-like protein family. It is secreted in the airway mucosa by the inflammatory cells that reside in the bronchial mucosal and airway epithelial cells [20-22]. Chitinase might contribute to the inflammation and bronchial remolding in $\mathrm{T}$ helper 2 (Th2)-airway inflammation, an immune response mediated condition. It has been reported that YKL-40 levels were increased in children with asthma and were correlated with the markers of disease severity [21]. The prognosis of hypersensitivity pneumonitis is also correlated with the serum levels of YKL-40 [12]. The admission level of YKL-40 in the serum could
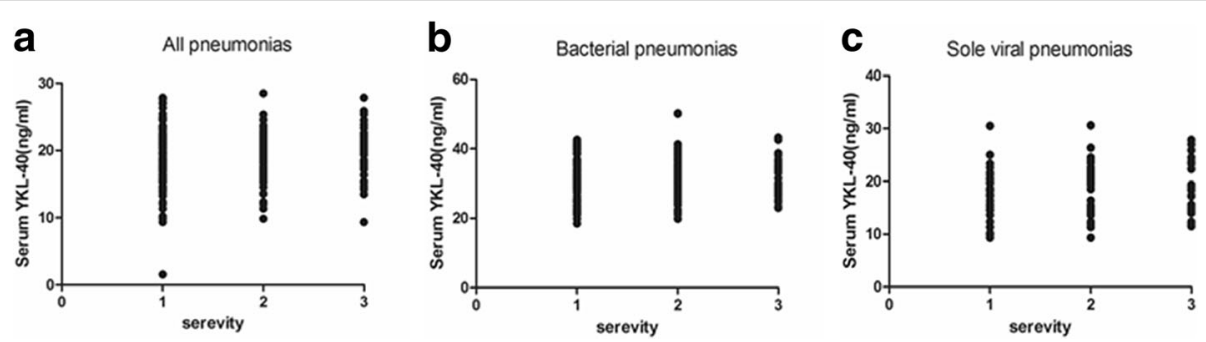

Fig. 3 The spearman correlation analysis between diseased severity and serum levels of YKL-40. a. The spearman correlation between severity and serum levels in all child pneumonia patients. No significant correlation was observed (spearman $r=0.066, P=0.28$ ). $\mathbf{b}$. The correlation between severity and serum levels in children patients with bacterial infection (spearman $r=0.16, P=0.09$ ). $\mathbf{c}$. The correlation between severity and serum levels in sole viral pneumonia patients (spearman $r=-0.19, P=0.12$ ). No significant correlation between admission levels and severity in all children with viral or bacterial pneumonia. $X$ axis represents the severity of childhood pneumonia. Non-severe pneumonia $=1$, severe pneumonia $=2$, very severe pneumonia $=3$ 

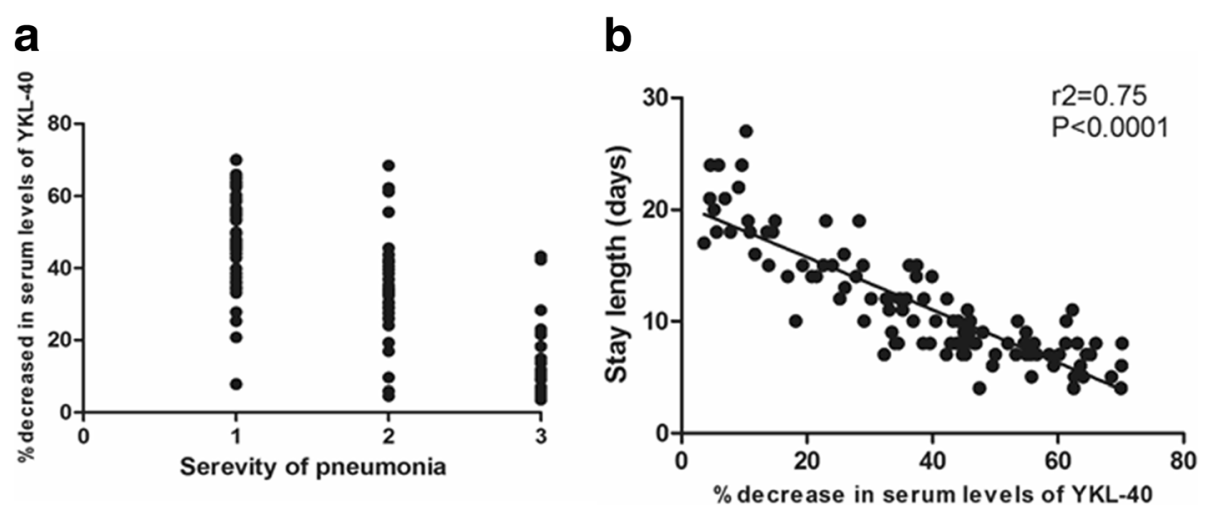

Fig. 4 The correlation between decreased percentage of serum levels of YKL-40 after 5th days and diseased severity. a. The correlation analysis between severity class and decreased percentage (spearman $r=-0.68, P<0.0001$ ). The negative correlation was verified by the spearman correlation analysis. $X$ axis represents the severity of childhood pneumonia. Non-severe pneumonia $=1$, severe pneumonia $=2$, very severe pneumonia $=3$. $\mathbf{b}$. The correlation analysis between severity class and median length of hospital stay $\left(r^{2}=0.75, P<0.0001\right)$. The hospitalization stays period was negatively correlated with decreased extent after admission. $P<0.05$ defined as significant statistic difference

predict disease progression and estimate mortality risk in patients with hypersensitivity pneumonitis. Meanwhile, in a cohorts of adults with CAP, the serum level was correlated with the pneumonia severity index, CURB-65 scores, length of hospital stay, and APACHE-II scores, which suggested that the levels of YKL-40 might have the potential to guide the treatment of CAP in adults [8].
We found that the higher admission level of YKL-40 in children with pneumonia than healthy volunteers. And the increased YKL-40 levels in BALFs compared to the serum levels was observed in the children with bacterial infection. In children with sole viral infection, the significant difference between the serum levels and BALFs levels of YKL-40, which might be attributed to the infiltrates being confined to within the pulmonary

Table 2 Logistics regression analysis for the factors associated with the prognosis of pneumonia

\begin{tabular}{|c|c|c|c|}
\hline & OR & $95 \% \mathrm{Cl}$ & $P$ value \\
\hline \multicolumn{4}{|l|}{ Rate of sepsis: Yes $(45,16.1 \%)$, No $(235,83.9 \%)$} \\
\hline Age (continuous variable) & 1.21 & $0.85,1.54$ & 0.652 \\
\hline Previous pneumonia(binary variable) & 0.92 & $0.85,1.24$ & 0.096 \\
\hline Decreased extent of YKL-40 (classified variable) & 2.84 & $2.16,3.65$ & 0.008 \\
\hline Infectious type (unordered variable) & 1.23 & $0.97,1.48$ & 0.078 \\
\hline Procalcitonin (continuous variable) & 1.12 & $1.03,1.22$ & 0.044 \\
\hline \multicolumn{4}{|c|}{ Mechanical ventilation rate: Yes (31, 11.1\%), No (249, 88.9\%) } \\
\hline Age (continuous variable) & 1.235 & $1.156,1.366$ & 0.023 \\
\hline Previous pneumonia (binary variable) & 2.02 & $1.68,2.26$ & 0.034 \\
\hline Decreased extent of YKL-40 (classified variable) & 1.69 & $1.26,2.08$ & 0.012 \\
\hline Infectious type (unordered variable) & 1.63 & $1.21,2.27$ & 0.028 \\
\hline Procalcitonin (continuous variable) & 1.021 & $0.916,1.148$ & 0.189 \\
\hline \multicolumn{4}{|c|}{ Intensive Care Unit admission rate: Yes (36, 12.9\%), No (244, 87.1\%) } \\
\hline Age (continuous variable) & 1.23 & $1.12,1.51$ & 0.041 \\
\hline Previous pneumonia (binary variable) & 1.21 & $0.93,1.87$ & 0.267 \\
\hline Decreased extent of YKL-40 (classified variable) & 3.21 & $2.68,4.79$ & 0.016 \\
\hline Infectious type (unordered variable) & 1.35 & $1.21,1.45$ & 0.030 \\
\hline Procalcitonin (continuous variable) & 1.09 & $0.91,1.17$ & 0.526 \\
\hline
\end{tabular}

Data are presented as hazard ratios, representing the relative risk of adverse therapeutic events and poor prognosis. The independent risk factors of mechanical ventilation including the age, infectious type, infections history in the previous and decreased extent of YKL-40. The age, infectious type, decreased extent of YKL40 not associated with the increased rate of mechanical ventilation but also considered as the independent risk factors of ICU admission 
interstitial lesion in most cases of viral pneumonia. But it did not predict the disease severity of pneumonia in children, which differs for the finding in adults. A previous study found that immune dysfunction was associated with increased disease severity in infants [23, 24]. This suppression of the adaptive immune response also has an adverse influence on the prognosis in septic children [25]. Therefore, the fact that there is no correlation between admission levels of YKL-40 and diseased severity might be attributed to the YKL-40 levels, which are decreased in the immunocompromised status of the severe cases in children, relative to the mild and slight cases [26]. In addition, the results are different from the finding in adults with CAP as mentioned in the introduction section. Therefore the admission levels of circulating YKL-40 have little correlation with the severity of pneumonia, which might be due to the immune suppression status for severe infectious pneumonia in children.

We noticed that the YKL-40 levels of BALF specimens were higher than the peripheral circulation in bacterial pneumonia, which support the fact suggestion that YKL-40 is secreted by the locally infiltrated inflammatory cells. To verify the correlation between the serum levels of classical pro-inflammatory cytokines and the BALF levels of YLK-40, we performed a linear correlation analysis. The levels of YKL-40 in the BALF specimens is positively correlated with the serum levels of CRP, which suggested that the level of YKL-40 in BALF specimens represented only the activity of inflammation at the lesion location rather than the systemic inflammation due to the endotoxin release or inflammation cascade. However, the difficulty in obtaining BALF samples limits its utilization for the repeated detection of admission levels of YKL-40 for monitoring diseased status. In a previous study associated with cystic fibrosis, Fantino et al. revealed that only the airway local levels of YKL-40 reflected the activity in lung tissue for the infant and young children with early cystic fibrosis [27]. The results above demonstrated that YKL-40, secreted by neutrophils, often serves as a confined inflammatory cytokine and is enriched in local inflammatory tissue rather than being released into the peripheral circulation. Therefore, it also could partly explain why the admission levels of YKL-40 were not correlated with the disease severity of pneumonia.

Eventually, to illustrate the predictive value in the evaluation of reduction degree serum levels of YKL-40 in children viral pneumonia, we applied the multivariable logistic regression analysis to explore the independent risk factors that might be correlated with prognosis. We found the reduction degree of YKL-40 is negative correlated with the admission of ICU, incidence of mechanical ventilation and sepsis. The results demonstrated that the reduction degree of YKL-40 levels, serving as a pro-inflammatory cytokine, was associated with the prognosis of child pneumonia, including the median length of stay, sepsis rate, mechanical ventilation rate, and ICU admission rate.

\section{Study limitation}

In the study, there were still several study limitations that should be taken into account in further and in-depth investigation. At first, we could not collect the BALF specimen because of the difficulty in the taking samples although the fact that the secretion of YKL-40 were produced by local inflammatory cells resident in respiratory tract. Secondly, the predictive value of degree of reduction in serum levels YKL-40 after 5 days compared than the admission levels was only available in the children with sole viral pneumonia, which might limit the more comprehensive application of this biomarker in clinical practice.

\section{Conclusions}

In conclusion, the degree of reduction of YKL-40 in the serum has a potential value in the prognostic assessment and prediction of disease severity. The YKL-40 levels in BALF specimens might reflect inflammatory activity at the lesion location and disease severity. Our study indicated that dynamically monitoring the levels of this inflammatory cytokine has potential value in the assessment of infectious diseases in children. More prospective clinical trials are needed to verify our finding.

\section{Abbreviations \\ BALF: Bronchoalveolar lavage; CAP: Community-acquired pneumonia; ELISA: Enzyme-linked immunoassay; HP: Hypersensitivity pneumonia; ICU: Intensive care unit; IL: Interleukin; ILD: Interstitial lung disease; PSI: Pneumonia severity index; Th2: T helper 2}

\section{Acknowledgements \\ Not applicable}

\section{Funding}

Not applicable

\section{Availability of data and materials}

The data that support the findings of this study are available from Electronic Medical Record System of The First Affiliated Hospital of Zhengzhou University but restrictions apply to the availability of these data, which were used under license for the current study, and so are not publicly available. Data are however available from the authors upon reasonable request and with permission of MEDICAL RECORD MANAGEMENT DEPARTMENT.

\section{Authors' contributions}

In this work, both authors conceived the study and designed the experiments; contributed to the data collection, performed the data analysis and interpreted the results; YXG wrote the manuscript; SGY contributed to the critical revision of article; both of them read and approved the final manuscript. 


\section{Ethics approval and consent to participate}

Written informed consent for all participants in the present study were obtain from these parents or guardians of these children before the performance of the study. The retrospective observation study was approved and reviewed by Medical ethic committee of the First Affiliated Hospital of Zhengzhou University.

\section{Consent for publication}

Not applicable

\section{Competing interests}

The authors declare that they have no competing interests.

\section{Publisher's Note}

Springer Nature remains neutral with regard to jurisdictional claims in published maps and institutional affiliations.

Received: 29 June 2018 Accepted: 13 November 2018

Published online: 04 December 2018

\section{References}

1. Ruuskanen O, Lahti E, Jennings LC, Murdoch DR. Viral pneumonia. Lancet. 2011;377:1264-75.

2. Walker CLF, Rudan I, Liu L, Nair H, Theodoratou E, Bhutta ZA, et al. Global burden of childhood pneumonia and diarrhoea. Lancet. 2013;381:1405-16.

3. Bhutta ZA, Das JK. Global burden of childhood diarrhea and pneumonia: what can and should be done? Pediatrics. 2013;131:634-6.

4. Floyd J, Wu L, Hay Burgess D, Izadnegahdar R, Mukanga D, Ghani AC. Evaluating the impact of pulse oximetry on childhood pneumonia mortality in resource-poor settings. Nature. 2015;528:S53-9.

5. Chiu CY, Chen CJ, Wong KS, Tsai MH, Chiu CH, Huang YC. Impact of bacterial and viral coinfection on mycoplasmal pneumonia in childhood community-acquired pneumonia. J Microbiol Immunol Infect. 2015:48:51-6.

6. Boyd K. Back to the basics: community-acquired pneumonia in children. Pediatr Ann. 2017:46:e257-61.

7. Libreros S, Iragavarapu-Charyulu V. YKL-40/CHI3L1 drives inflammation on the road of tumor progression. J Leukoc Biol. 2015;98:931-6.

8. Kastrup J. Can YKL-40 be a new inflammatory biomarker in cardiovascular disease? Immunobiology. 2012;217:483-91.

9. Wang HL, Hsiao PC, Tsai HT, Yeh CB, Yang SF. Usefulness of plasma YKL-40 in management of community-acquired pneumonia severity in patients. Int J Mol Sci. 2013;14:22817-25.

10. Furuhashi $K$, Suda T, Nakamura $Y$, Inui N, Hashimoto D, Miwa S, et al. Increased expression of YKL-40, a chitinase-like protein, in serum and lung of patients with idiopathic pulmonary fibrosis. Respir Med. 2010; 104:1204-10.

11. Johansen JS, Milman N, Hansen M, Garbarsch C, Price PA, Graudal N Increased serum YKL-40 in patients with pulmonary sarcoidosis--a potential marker of disease activity? Respir Med. 2005;99:396-402.

12. Long X, He X, Ohshimo S, Griese M, Sarria R, Guzman J, et al. Serum YKL-40 as predictor of outcome in hypersensitivity pneumonitis. Eur Respir J. 2017. https://doi.org/10.1183/13993003.01924-2015.

13. Harris M, Clark J, Coote N, Fletcher P, Harnden A, McKean M, et al. British Thoracic Society guidelines for the management of community acquired pneumonia in children: update 2011. Thorax. 2011:66:ii1-23.

14. Eccles S, Pincus C, Higgins B, Woodhead M. Guideline Development Group Diagnosis and management of community and hospital acquired pneumonia in adults: summary of NICE guidance. BMJ. 2014;349:96722.

15. Abers MS, Musher DM. The yield of sputum culture in bacteremic pneumococcal pneumonia after initiation of antibiotics. Clin Infect Dis. 2014;58:1782-3.

16. Jiang W, Wu M, Zhou J, Wang Y, Hao C, Ji W, et al. Etiologic spectrum and occurrence of coinfections in children hospitalized with communityacquired pneumonia. BMC Infect Dis. 2017:17:787.

17. Scott JA, Wonodi C, Moïsi JC, Deloria-Knoll M, DeLuca AN, Karron RA, et al, The definition of pneumonia, the assessment of severity, and clinical standardization in the pneumonia etiology research for child health study. Clin Infect Dis. 2012;54:S109-16.

18. Bradley JS, Byington CL, Shah SS, Alverson B, Carter ER, Harrison C, et al. The management of community-acquired pneumonia in infants and children older than 3 months of age: clinical practice guidelines by the Pediatric
Infectious Diseases Society and the Infectious Diseases Society of America. Clin Infect Dis. 2011:53:e25-76.

19. Marguet C, Dean TP, Warner JO. Soluble intercellular adhesion molecule-1 (sICAM-1) and interferon-gamma in bronchoalveolar lavage fluid from children with airway diseases. Am J Respir Crit Care Med. 2000;162:1016-22.

20. Specjalski K, Chelminska M, Jassem E. YKL-40 protein correlates with the phenotype of asthma. Lung. 2015;193:189-94.

21. Konradsen JR, James A, Nordlund B, Reinius LE, Söderhäll C, Melén E, et al. The chitinase-like protein YKL-40: a possible biomarker of inflammation and airway remodeling in severe pediatric asthma. J Allergy Clin Immunol. 2013; 132:328-35 e5.

22. Waldon EG, Lesser A, Weeden L, Messick E. The music attentiveness screening assessment, revised (MASA-R): a study of technical adequacy. J Music Ther. 2016;53:75-92.

23. García C, Soriano-Fallas A, Lozano J, Leos N, Gomez AM, Ramilo O, et al. Decreased innate immune cytokine responses correlate with disease severity in children with respiratory syncytial virus and human rhinovirus bronchiolitis. Pediatr Infect Dis J. 2012;31:86-9.

24. Mella C, Suarez-Arrabal MC, Lopez S, Stephens J, Fernandez S, Hall MW, et al. Innate immune dysfunction is associated with enhanced disease severity in infants with severe respiratory syncytial virus bronchiolitis. J Infect Dis. 2013:207:564-73.

25. Muszynski JA, Nofziger R, Greathouse K, Steele L, Hanson-Huber L, Nateri J, et al. Early adaptive immune suppression in children with septic shock: a prospective observational study. Crit Care. 2014;18:R145.

26. Gudmundsdottir S, Lieder R, Sigurjonsson OE, Petersen PH. Chitosan leads to downregulation of YKL-40 and inflammasome activation in human macrophages. J Biomed Mater Res A. 2015;103:2778-85.

27. Fantino $E$, Gangell CL, Hartl D, Sly PD, Airway ARESTCF. But not serum or urinary, levels of YKL-40 reflect inflammation in early cystic fibrosis lung disease. BMC Pulm Med. 2014:14:28.

\section{Ready to submit your research? Choose BMC and benefit from:}

- fast, convenient online submission

- thorough peer review by experienced researchers in your field

- rapid publication on acceptance

- support for research data, including large and complex data types

- gold Open Access which fosters wider collaboration and increased citations

- maximum visibility for your research: over $100 \mathrm{M}$ website views per year

At BMC, research is always in progress.

Learn more biomedcentral.com/submissions 